\title{
Discursos políticos sobre la inmigración presentes en los programas de gobierno del proceso electoral de Costa Rica 2017-2018
}

Recibido: 20 de enero 2019

Revisado: 39 de enero 2019

Aprobado: 26 de abril 2019

José Daniel Rodríguez

Arrieta

Costarricense. Licenciado en

Ciencias Políticas por la

Universidad de Costa Rica.

Es profesor e investigador

de la Escuela de Ciencias

Políticas de la Universidad

de Costa Rica, San José,

Costa Rica. Trabaja en temas de migración, refugio, derechos humanos, análisis de discurso y comunicación para el cambio social. Correo electrónico: josedanielcr@gmail.com

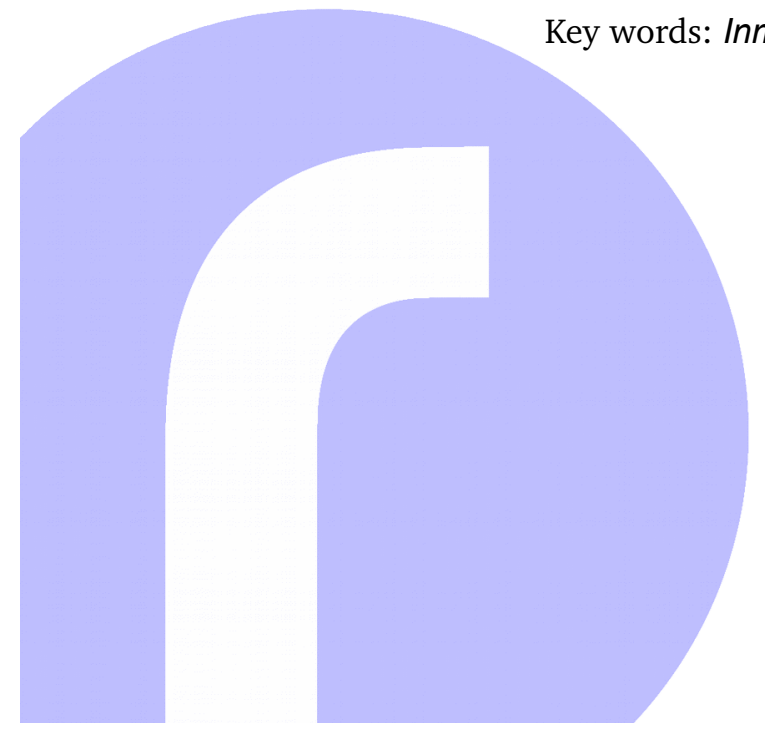

https://revistas.uned.ac.cr/index.php/rupturas (c) (1)(2)
Resumen: El presente artículo sistematiza y analiza los discursos políticos presentes en los programas de gobierno acerca de la inmigración y las personas inmigrantes, de los partidos nacionales inscritos para las elecciones de Presidencia y diputaciones de Costa Rica durante la campaña 2017-2018. Para ello, se propone un estudio de tales discursos en un continuum entre discursos re-activos y discursos proactivos frente al fenómeno inmigratorio, lo cual evidencia la concepción de los partidos políticos como actores fundamentales en la formulación de las políticas públicas que afectarán a la población inmigrante.

Palabras clave: Inmigración; elecciones; política; migración

\section{Presence of political discourses regarding immigration within the} government programs for the elections in Costa Rica, 2017-2018

Abstract: The present paper systematizes and provides an analysis of the political discourses regarding the topics of immigration and immigrants, presented in the government proposals of the national political parties participating during the presidential and legislative elections, in Costa Rica, for the period 2017-2018.The proposal focuses in the discourses, considering them as a continuum between re-active and pro-active discourses facing the immigration phenomenon, situation which evidences the conception of the political parties as fundamental actors in the formulation of public policies that will affect the immigrant population.

Key words: Inmigration; elections; politics; migration 


\section{Presentación}

En los años recientes, el tema de la migración se ha visto envuelto en polémica, y ha sido objeto de discusión permanente pues integra complejos discursos de economía, trabajo o derechos humanos entre los principales; al tiempo que despierta discursos extremos de grupos opuestos a la inmigración.

Las políticas migratorias son, en muchos casos, resultado de una constante negociación política de diversos actores como los partidos políticos, los gobiernos centrales y, óptimamente, la sociedad civil; todo ello tiene el potencial de reflejar la percepción que sobre la migración tiene una sociedad dada en un momento determinado; aunque esto es ciertamente cada vez más complicado, debido, entre otras razones, a una crisis de representación. Pero cabe apuntar que también dichas políticas pueden ser estrictamente una propuesta unilateral de las élites políticas.

Los sistemas democráticos liberales delegan la formulación de políticas públicas en los poderes Ejecutivo y Legislativo, lo cual implica que el elemento político-electoral es un paso inicial para la elaboración y su posterior implementación o cualesquiera políticas. Así, la compresión y el análisis de estos procesos políticos pasa por entender y desgranar los discursos políticos detrás de los enunciados sobre los diversos temas de la sociedad, en particular para nuestro interés, el de la inmigración.

El migrante, de acuerdo con la Organización Internacional para las Migraciones (OIM) es:

Cualquier persona que se desplaza o se ha desplazado a través de una frontera internacional o dentro de un país, fuera de su lugar habitual de residencia independientemente de: 1) su situación jurídica; 2) el carácter voluntario o involuntario del desplazamiento; 3) las causas del desplazamiento; o 4) la duración de su estancia (2019).

Tal definición con claridad expresa, aunque sea redundante reiterarlo, que los que migran son personas, lo que implica, desde un punto de vista de políticas públicas, que debe tomarse en cuenta las características complejas de la persona humana cuando se legisla sobre este proceso; o, al menos, este es el deber ser. De ese modo, se reconoce que el inmigrante es la persona que entra a un país o una región delimitada por fronteras, y de las cuales no es originario.

A partir de lo anterior, la búsqueda de elementos para entender los discursos sobre inmigración de las sociedades pasa por detectar en la génesis de los programas de gobierno los criterios, códigos y marcos de referencia sobre los 
cuales se desarrollan los discursos políticos acerca de inmigración; en este caso, tal génesis son los planes programáticos para gobernar, en Costa Rica, y en adelante conocidas como programas de gobierno.

Por sus características sociales, geográficas y económicas, Costa Rica es un país de origen, tránsito y destino de población migrante. Ello implica que las políticas formuladas para gestionar los procesos migratorios son complejas. Entonces, visualizar los programas de gobierno y sistematizarlos a partir de una herramienta determinada, nos brinda un panorama importante de cómo se comprende, desde los planes de gobierno, el fenómeno migratorio; al tiempo que se identifican para posteriormente evaluar las acciones políticas al ocupar los cargos políticos formales.

Para concretar el análisis, se recurre a fundamentos teóricos y metodológicos del politólogo Ricard Zapata-Barrero de lo que llama política del discurso. Se dividen los discursos políticos en dos grandes categorías, proactivos y reactivos, con respeto a los discursos sobre la multiculturalidad. A partir de palabras clave, se infieren criterios básicos para dividir los discursos presentes en los programas de gobierno escogidos en tales categorías y, así, finalmente, sistematizar los discursos identificados por posiciones y actores.

\section{Elecciones presidenciales y programas de gobierno en un país de características migratorias}

Como se ha mencionado, Costa Rica es un país históricamente relacionado con los fenómenos migratorios. Tal cual lo desarrolla Alvarenga, la escasa población de Costa Rica a finales del siglo XIX conllevó a una política de atracción de inmigración y colonización de una población específicamente europea; lo anterior por la percepción histórica de una 'nación blanca', prohibiendo, incluso, la colonización de "razas africanas y chinas" $(2008,5)$.

Asimismo, Alvarenga $(2008,6)$ recuerda que "los proyectos migratorios existentes entre 1880 y 1950 fueron pocos, pero muy ambiciosos", relacionados, entre otras actividades, a la construcción del ferrocarril al Atlántico y colonización de tierras ociosas.

Pero, en términos generales, en el siglo $X X$ "hay una clara tendencia al predominio de la población migrante de otros países centroamericanos (Nicaragua y Panamá en primero y segundo lugar, respectivamente)" (Alvarenga 2008, 6); La relativa estabilidad comparativa, tanto en términos políticos como económicos, ha posicionado a Costa Rica como país receptor y la tendencia es que estos sean de carácter permanente (SICREMI, 2015).

El último censo realizado en Costa Rica, en 2011, arrojaba el dato de 385 mil 899 personas nacidas en otro país (DGME, 2012), lo cual significaba el 9\% de la población total, además de ser en ese momento el país latinoamericano con más porcentaje de inmigrantes registrados dentro de sus fronteras. De acuerdo con datos brindados por OCDE/OIT (2018), Costa Rica experimentó 
un aumento sostenido en la inmigración entre 2005 y 2015; este último es el dato más reciente en dicha referencia.

Asimismo, el mencionado informe explica que los nacidos en el exterior tienen una tasa de empleo muy alta, lo que implica que su aporte a la fuerza laboral es fundamental, en un país con un fuerte componente del PIB proveniente del sector servicios (Estado de la Nación, 2016, OCDE/OIT, 2018). Por otra parte, de acuerdo con Morales (2014), la mano de obra inmigrante, particularmente nicaragüense, es fundamental para el sector construcción, el cual es empleado alrededor de $65 \%$. Otro elemento relevante es que la inmigración también cumple la función de contrarrestar el envejecimiento de la fuerza laboral del país, lo cual queda demostrado en las tendencias demográficas del país (OCDE/OIT, 2018).

Es claro, hasta este punto, que la fuerza laboral inmigrante un componente importante para Costa Rica (OCDE/OIT, 2018) el tema no es profundizado en campañas políticas como una temática relevante.

Pero el hecho de que la situación no se aborde, no implica 1) que no goce de importancia para el desarrollo de la sociedad de acogida, 2) que no plantee retos y problemas que deben ser solucionados y 3) que no esté presentes en los programas de gobierno, precisamente por la existencia, finalmente, de los dos puntos previos.

En un breve repaso por las diversas definiciones clásicas y contemporáneas de partido político, se evidencia con claridad que el hecho de poseer un programa o plan para gobernar no es un requisito básico en función del objetivo de ostentar el poder, lo cual es la característica ineludible de estos colectivos de acuerdo con autores clásicos como Duverger (1972) o Janda (1980). Diversos politólogos establecen la presencia de un programa de gobierno como una característica que les diferencia de otros actores políticos.

Oñate $(2003,253)$ explica que los partidos se caracterizan, entre otras razones, por poseer "un programa de gobierno con objetivos a alcanzar, por mínimo y abstracto que sea". Por su parte, Dalmases $(2005,318)$ afirma que los partidos contemporáneos -en contraposición a los presentes hasta la primera mitad del siglo $X X-$, entre otros elementos, "elaboran programas políticos de gobierno concebidos para el conjunto de la sociedad". Entonces, sobre esta línea, Molina (2007, 102) define programa de gobierno electoral -dentro de una definición más amplia de 'programa político'- como "un documento que se ofrece al votante y donde se concretan las propuestas que una candidatura pretende materializar si es elegida".

Es preciso entender que estos documentos se presentan como la "base" de trabajo del partido -y el candidato en particular- en caso de obtener la Presidencia de la República; pero también es el fundamento de la acción, como en el caso particular costarricense, de los representantes elegidos para el Poder Legislativo.

Un programa de gobierno responde -es de esperar- al proyecto político de un partido determinado. Esto podría basarse en una ideología a la cual se 
adhiere discursivamente (aunque no necesariamente) el partido y es "un compromiso concreto, una propuesta de intercambio de problemas, tiene que resolver el conflicto de valores, tiene que ser viable, tiene que ser operacional y tiene que ser aceptable" (Matus 2007, 207).

Asimismo, de acuerdo con PNUD $(2015,13)$, el programa de gobierno, desde lo político,

Es un instrumento que, por ser de obligatorio cumplimien-

to a través del plan de desarrollo, constituye el punto de

partida para el ejercicio del control político y del control

social y del proceso de rendición de cuentas a la ciudada-

nía.

Es decir, los programas de gobierno establecen, en principio, el marco de referencia gubernamental y partidario para el ejercicio del poder.

Los discursos sobre inmigración dados en el ámbito político, es un acto político. Implica que, aunque como tal no tiene la vinculación y la formalidad de una política pública, sí tiene el peso discursivo del acto político mismo, lo cual se desarrollará en el siguiente apartado.

Por ende, los programas de gobierno son una expresión de intenciones políticas derivadas de relaciones ideológicas dentro de los partidos políticos y, así, a la vez, son parte fundamental del discurso político de estas agrupaciones, lo que eventualmente se convertirá en la base del discurso político de ejercicio desde el Ejecutivo, el Legislativo o ambos.

En el proceso electoral de Costa Rica 2017-2018 participaron 13 partidos políticos a nivel nacional, por lo cual se produjeron 13 programas de gobierno, lo que se convierte en el material base para la presente investigación.

\section{Los programas de gobierno, el discurso político y la Política del discurso}

Zapata-Barrero $(2007,2009)$ plantea que la construcción de un discurso es un acto político en sí mismo y, como tal, puede analizarse como una política misma. El enfoque de la política del discurso, desarrollado por este autor, otorga al "mismo discurso la categoría de una acción que busca tener efectos determinados sobre la ciudadanía" (2007, 319); esta es llevada a cabo por políticos y por partidos políticos.

Antes de ello, el análisis del discurso político sobre la inmigración reviste de una gran importancia a la hora de construir las posibles interpretaciones sobre la variada cantidad de elementos que confluyen en los procesos migratorios y las concepciones relacionadas; el fenómeno específico de la inmigra- 
ción es uno de las más determinantes. De esa manera lo plantean ZapataBarrero, González y Sánchez $(2008,16)$ :

El análisis del discurso constituye un indicador que nos ayuda a entender en qué momento estamos del proceso de cambio. Desde la perspectiva discursiva, se puede definir 'conflicto' como la existencia de muchas interpretaciones que, de alguna manera, están enfrentadas entre sí. Por lo tanto, un conflicto socio-político genera discursos diferentes dentro de las redes discursivas. El discurso no describe solamente el conflicto, sino que lo explica e intenta proponer soluciones.

Lo anterior entiende, entre lo primordial, el cambio como un resultado y, podría agregarse origen, del proceso de la multiculturalidad de acuerdo a los autores, pero que efectivamente también puede entenderse desde la inmigración propiamente. Asimismo, ese cambio (o la posibilidad de éste) también se puede ver en la comparación entre programas de gobierno de partidos políticos; precisamente, la perspectiva discursiva evidencia las diversas interpretaciones (que los autores definen como 'conflicto') acerca de la inmigración desde las varias posturas presentes en los programas de gobierno como textos de estudio.

Referirse a 'discurso' es ubicar la unidad de análisis en la relación entre el texto y el contexto (Van Dijk, 1993). ¿Qué podemos comprender por discurso? En primera instancia, es un concepto polisémico el cual ha sido muy desarrollado y desde diversas ópticas epistemológicas.

Sobre ello, Jäger $(2003,63)$, siguiendo a Link, lo explica como "un concepto de habla que se encontrará institucionalmente consolidado en la medida que determine y consolide la acción y, de este modo, sirva ya para ejercer el poder". Es importante ya que identifica en la definición misma del concepto el carácter subjetivo y cargado en función de su utilización para fines políticos, demostrando en sí mismo el peso de su uso.

Por su parte, Wodak y Meyer $(2003,104)$, apoyándose en Fairclough, definen un discurso como "una forma de significar un particular ámbito de la práctica social desde una particular perspectiva". Esto hace una imprescindible referencia al componente del discurso en tanto un acto específico a partir de un punto de vista particular, lo cual puede trasladarse al acto político.

Sobre esta línea, Zapata-Barrero $(2009,48)$ apunta acertadamente que "al hablar de discurso, nuestra unidad de análisis es la relación entre texto y contexto". Desde dicho punto de partida, puede afirmarse que, al ubicar un texto en su contexto, se establece una delimitación temporal y espacial a los significados que dicho texto puede tener; es decir, sin comprender $-\mathrm{u}$ omitir- 
el contexto en el cual se ubica el texto, es muy difícil que pueda tenerse un discurso.

A partir de lo anterior recae la importancia del estudio del discurso y sus componentes, al reconocer la existencia de los conflictos sociales. En ese sentido, Zapata-Barrero $(2009,16)$ apunta:

El análisis del discurso constituye un indicador que nos ayuda a entender en qué momento estamos del proceso de cambio. Desde la perspectiva discursiva, se puede definir 'conflicto' como la existencia de muchas interpretaciones que, de alguna manera, están enfrentadas entre sí. Por lo tanto, un conflicto socio-político genera discursos diferentes dentro de las redes discursivas. El discurso no describe solamente el conflicto, sino que lo explica e intenta proponer soluciones.

Por lo tanto, inicialmente un discurso puede definirse como "una articulación de interpretaciones, e 'interpretaciones' como la asignación de sentido" (Zapata-Barrero 2009, 48). Y a partir de un contexto particular, el discurso articula de una forma determinada los diversos sentidos que las personas asignan a las cosas. Entonces, el discurso político hegemónico -el expresado desde las élites- sobre inmigración en Costa Rica, depende de los elementos contextuales del momento en el que se efectúa, quiénes lo dicen y desde cuál posición.

Lo anterior implica, como lo explica Zapata Barrero $(2009,48)$, que situar un texto en su contexto respectivo es "delimitar la gama de significados relacionados con el primero"; o sea que debe reconocerse cuáles son las características que definen el contexto para ubicar el texto en el mismo y así derivar en un discurso.

El discurso político es un producto de las "élites simbólicas" por naturaleza (Dobles, Amador, Arroyo y Vargas. 2013). Ello, entonces, puede explicarse como una intención de la clase política en función de un objetivo determinado. Tales discursos extienden una relación con el momento, el medio y su función, lo cual determina y modifica el contenido. Desde este punto de vista, el discurso político relativo a la inmigración inferible de los programas de gobierno, como acto político en sí, expresa metas, objetivos o como mínimo intenciones sobre acciones a tomar frente al fenómeno inmigratorio.

El enfoque de la política del discurso presta más cuidado en las respuestas de los actores políticos a las preguntas: ¿qué decimos?, ¿cómo los planteamos? (Zapata-Barrero 2009) y no en los ¿cómo lo hacemos? Es fundamental a la hora de evaluar los programas de gobierno como unidades de observación del presente trabajo. 


\section{Discursos re-activos $y$ discursos pro-activos acerca de la inmigración}

Normalmente, los trabajos dedicados al estudio entre los vínculos sobre inmigración y discurso se han posicionado desde el análisis del discurso racista (Zapata-Barrero 2009) y fundamentalmente a partir de estudios de discursos de medios de difusión. Asimismo, trabajos como el de van Dijk (2001, 2010) se han enfocado en estudios acerca del lingüismo y racismo.

A raíz de lo anterior, el enfoque de la política del discurso propone que la inmigración y la multiculturalidad son parte de "un proceso de cambio histórico, la lógica que prevalece ya no es la del racismo en todas sus formas, sino la que tiene en cuenta un nuevo paradigma dominante entre la monoculturalidad-pasada y la multiculturalidad-futura" $(2009,58)$.

Ello deriva, a partir de este enfoque, en la potencialidad del surgimiento de dos tipos de discurso en torno a la inmigración: un discurso re-activo (el cual es efectivamente una reacción al proceso histórico de la multiculturalidad e igualmente a la inmigración, buscando una vuelta al pasado monocultural); y un discurso pro-activo (que reconoce el proceso irreversible de la multiculturalidad, y apuesta por su gestión).

Precisamente, tales categorías sirven metodológicamente para la comprensión de los discursos en torno a la inmigración, proveyendo un marco clasificatorio y analítico de los programas de gobierno, reconociéndoles como discursos políticos, sobre la inmigración propiamente.

Una diferenciación fundamental que define la distinción analítica de cada discurso es que cada uno de los discursos -re-activo y pro-activo- parte de una concepción distinta sobre el origen de la discusión acerca de la inmigración; esto es, que los marcos de referencia varían y se excluyen, dependiendo de cada caso en particular.

Este enfoque, para efectos analíticos, interpreta la contraposición de los procesos históricos -mencionados en párrafos previos- como un conflicto. El discurso re-activo "interpreta el conflicto como algo negativo, como una amenaza. Es visto básicamente como conflicto de intereses entre inmigrantes y ciudadanos" (Zapata Barrero 2009, 58); o sea, existe un componente 'invasivo' en el inmigrante -sobre todo el inmigrante económico-, que actúa en detrimento de los ciudadanos nacionales.

El discurso pro-activo entiende el conflicto en términos de una "oportunidad histórica y un reto que hay que afrontar y que forma parte del proceso de socialización en el que está envuelta nuestra sociedad" (Zapata Barrero 2009, 58), lo que significa que el proceso de inmigración existe y debe canalizarse en términos de comprenderle como una parte natural de la evolución social, y que excluye potencialmente el factor 'invasivo' propio del discurso re-activo.

Un punto en común, pero que a la vez difiere ambos discursos, es que para enfrentar el conflicto, los dos se basan en principios de justicia, aunque desde perspectivas muy diferentes: 
El discurso re-activo busca gestionar el conflicto y se preocupa por las alteraciones negativas que supone el proceso de multiculturalidad en todas las esferas de la vida. El discurso pro-activo aspira a proporcionar a las personas recursos e instrumentos para que gestionen los conflictos que son percibidos como un hecho histórico irreversible (Zapata Barrero 2009, 58).

Para comprender de forma sistemática otros puntos de comparación entre ambos discursos, se presenta la siguiente tabla:

Tabla 1. Temas y subcategorías para la definición de los discursos políticos en torno a la inmigración en los programas de gobierno 2017-2018 y los discursos correspondientes

\begin{tabular}{|c|c|c|c|}
\hline & Discurso re-activo & Discurso pro-activo \\
\hline \multicolumn{4}{|c|}{ A. INTERPRETACIÓN DEL FENÓMENO MIGRATORIO } \\
\hline a.1 & $\begin{array}{l}\text { Percepción } \\
\text { sobre } \\
\text { inmigración. la }\end{array}$ & $\begin{array}{l}\text { Identifica la inmigración } \\
\text { como un problema } \\
\text { (estrechamente ligado al } \\
\text { crimen transnacional) a } \\
\text { resolverse con coerción, } \\
\text { legalización de la población } \\
\text { o a partir de los tribunales. }\end{array}$ & $\begin{array}{l}\text { La inmigración es un reto, en } \\
\text { tanto el respeto de sus } \\
\text { derechos así como la } \\
\text { integración de esta población a } \\
\text { la sociedad de acogida. }\end{array}$ \\
\hline \multicolumn{4}{|c|}{ B. INTERPRETACIÓN DEL INMIGRANTE } \\
\hline b.1 & $\begin{array}{l}\text { Nombre } \\
\text { concepción } \\
\text { sobre } \\
\text { inmigrante. }\end{array}$ & 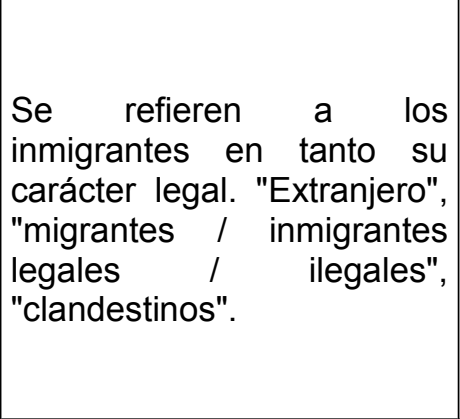 & $\begin{array}{l}\text { Toma en cuenta elementos de la } \\
\text { complejidad del proceso } \\
\text { migratorio, y utiliza palabras con } \\
\text { una carga más neutral, optando } \\
\text { poco por el uso de palabras } \\
\text { relativas a status legal. Es } \\
\text { importante } \text { que r utiliza } \\
\text { normalmente el sustantivo } \\
\text { 'persona' antes del carácter } \\
\text { migrante. }\end{array}$ \\
\hline b.2 & $\begin{array}{lr}\text { Actividades } & \text { y } \\
\text { funciones } & \text { del } \\
\text { inmigrante. } & \end{array}$ & \begin{tabular}{|lrrr} 
Ubica al & inmigrante romo \\
proclive & a & realizar \\
actividades & ilícitas & o \\
ninguna & actividad & en \\
particular. & & & \\
\end{tabular} & $\begin{array}{l}\text { Interpreta al inmigrante a partir } \\
\text { del aporte o potencial aporte a } \\
\text { la sociedad de acogida, } \\
\text { comprendiendo actividades } \\
\text { ilegales como una excepción. }\end{array}$ \\
\hline \multicolumn{4}{|c|}{ C. LEY Y POLÍTICA MIGRATORIA } \\
\hline c.1 & Objet & $\begin{array}{|lcr|}\text { Base } & \text { normativa } & \text { principal } \\
\text { para } & \text { establecer } & \text { la }\end{array}$ & $\begin{array}{llll}\text { Medio para integrar } & \text { a la } \\
\text { población inmigrante } & \text { a } & \text { la }\end{array}$ \\
\hline
\end{tabular}




\begin{tabular}{|c|c|c|c|}
\hline & & $\begin{array}{l}\text { restricción del ingreso de la } \\
\text { población inmigrante. }\end{array}$ & $\begin{array}{|ll|}\text { sociedad de acogida. Debe ser } \\
\text { transversalizada por los } \\
\text { derechos humanos. }\end{array}$ \\
\hline c. 2 & Debilidades. & \multicolumn{2}{|c|}{ Se entiende a partir de las carencias en los objetivos. } \\
\hline \multicolumn{4}{|c|}{ D. POLÍTICA EXTERIOR } \\
\hline d. 1 & $\begin{array}{l}\text { Relación con la } \\
\text { población } \\
\text { inmigrante. }\end{array}$ & $\begin{array}{l}\text { Búsqueda de apoyo para un } \\
\text { accionar común en función } \\
\text { de políticas restrictivas. }\end{array}$ & $\begin{array}{l}\text { Los acuerdos multilaterales y } \\
\text { bilaterales deben enfocarse en } \\
\text { ayuda humanitaria y en aportar } \\
\text { en proceso migratorios que } \\
\text { respeten los derechos } \\
\text { humanos. }\end{array}$ \\
\hline \multicolumn{4}{|c|}{ E. TEMAS BÁSICOS } \\
\hline e.1 & $\begin{array}{l}\text { Servicios } \\
\text { públicos. }\end{array}$ & $\begin{array}{l}\text { El acceso a servicios debe } \\
\text { estar condicionado al status } \\
\text { legal. Los inmigrantes } \\
\text { tienden a abusar de los } \\
\text { servicios públicos. }\end{array}$ & $\begin{array}{l}\text { Los inmigrantes son también } \\
\text { beneficiarios de los servicios } \\
\text { públicos. }\end{array}$ \\
\hline e.2 & Desarrollo. & $\begin{array}{l}\text { Los flujos migratorios son } \\
\text { parte de la maquinaria } \\
\text { productiva, pero no se } \\
\text { identifica como personas } \\
\text { individuales. Su estadía } \\
\text { depende directamente de la } \\
\text { posesión de trabajo. }\end{array}$ & $\begin{array}{l}\text { El inmigrante es un componente } \\
\text { activo. Es una persona que } \\
\text { aporta al desarrollo de la } \\
\text { sociedad de acogida. }\end{array}$ \\
\hline e.3 & Seguridad. & $\begin{array}{l}\text { La inmigración es un asunto } \\
\text { de seguridad } \\
\text { primordialmente. } \\
\text { permea el accionar de } \\
\text { sistema a partir de la } \\
\text { "seguridización". }\end{array}$ & $\begin{array}{l}\text { La seguridad no es componente } \\
\text { único ni el principal en cuestión } \\
\text { de su relación con la } \\
\text { inmigración. Y en el momento } \\
\text { de relacionarse, debe ser a } \\
\text { partir de un enfoque de } \\
\text { derechos humanos. }\end{array}$ \\
\hline \multicolumn{4}{|c|}{ F. RECONOCIMIENTO DE DERECHOS } \\
\hline f.1 & $\begin{array}{l}\text { Derechos que } \\
\text { deben } \\
\text { reconocerse o } \\
\text { profundizarse. }\end{array}$ & $\begin{array}{l}\text { El Estado tiene la } \\
\text { prerrogativa total de asignar } \\
\text { derechos a esta población, } \\
\text { partiendo de un criterio de } \\
\text { "interés nacional". No existe } \\
\text { ningún punto de partida que } \\
\text { equipare los derechos de } \\
\text { los inmigrantes al de los } \\
\text { nacionales. }\end{array}$ & $\begin{array}{l}\text { Los derechos no se asignan, se } \\
\text { reconocen. En calidad de } \\
\text { personas, los inmigrantes son } \\
\text { destinatarios naturales de los } \\
\text { Derechos. Fuerte presencia del } \\
\text { enfoque de los derechos } \\
\text { humanos. }\end{array}$ \\
\hline
\end{tabular}

Elaboración propia con elementos de Zapata-Barrero (2009). 
Finalmente, por una parte, Zapata-Barrero considera que la política del discurso re-activo está propenso a seguir tanto la retórica populista a partir de una base que denomina ciudadanismo en tanto "expresa una apelación constante a la ciudadanía en contraposición a los que no son ciudadanos (los inmigrantes)" (2009, 67).

Por otra parte, el discurso pro-activo se expresa en dos retóricas, la de la igualdad y la de la ciudadanía (Zapata-Barrero 2009, 94). La primera "expresa la necesidad de tener como criterio el principio de igualdad de oportunidades para gestionar las zonas de conflicto multiculturales"; la segunda es de un carácter más institucional en tanto argumenta en función de reconocer que en un momento final, el inmigrante debe ser reconocido como un ciudadano pleno.

Los fundamentos descritos hasta este punto destacan de forma general y muy puntualizada, para nuestros efectos, la propuesta teórica de Zapata-Barrero. Dichos insumos se muestran como el mínimo suficiente para comprender a cabalidad el aporte de este enfoque al análisis del discurso de los plantes de gobierno escogidos para estudiar.

\section{Metodología}

Partimos, como se anticipó, de la propuesta metodológica de Zapata-Barrero para el abordaje de las unidades de observación definidas: los programas de gobierno, particularmente en lo que respecta a la inmigración.

El objetivo es analizar los programas de gobierno presentados por los 13 partidos políticos para las elecciones presidenciales de 2017-2018 en lo relacionado específicamente en la temática de inmigración a partir del enfoque de la política del discurso. Es importante resaltar que la migración por turismo no se contempla dentro del análisis.

El método de la política del discurso implica efectuar un previo análisis del material duro -en este caso, los programas de gobierno- e inferir, en primer lugar, los tópicos (Zapata-Barrero 2009). Estos podrían considerarse como temáticas generales que van a generar una gama de significados e interpretaciones por parte de los actores políticos, lo que se especifica en el presente estudio para temas básicos relativos a la inmigración.

Asimismo, los tópicos aglutinan a su vez determinadas categorías o criterios sistematizados -también obtenidos por inferencia- que demuestran, a su vez, los discursos sobre el fenómeno de la inmigración, desde los discursos re-activo y pro-activo, en tanto objetos del enfoque de la política del discurso desarrollado previamente. Ante tal panorama, cabe aclarar que la inferencia se valida por cuanto no todas las categorías están presentes en los planes de gobierno; por ende, estas deben ser ubicadas en un primer momento.

La lectura de los programas de gobierno pasa, en primer lugar, por el análisis documental exhaustivo de estos para reconocer y resaltar la presencia de la 
temática de la inmigración de forma directa, o bien asociada a algún otro tema, pero que sea relevante para comprender el discurso sobre inmigración que subyace.

En segundo lugar, cuando ya se establecen las formas y los apartados en los cuales está presente cualquier variante atribuida al fenómeno de la inmigración, se sistematiza la información para inferir posteriormente los Tópicos y las categorías para caracterizar los marcos de referencia de los discursos re-activos y pro-activos presentes en los programas de gobierno (En la tabla 2 del siguiente apartado se detalla la ficha de los programas) para así clasificarlos y, finalmente, redondear en una interpretación a partir del enfoque de la política del discurso.

\section{¿Qué se encontró?}

La tabla 2 sistematiza el material recopilado con el cual se trabajó y especifica las siglas por utilizar en los siguientes apartados:

Tabla 2. Programas de gobierno analizados*

\begin{tabular}{|l|l|c|}
\hline \multicolumn{1}{|c|}{ SIGLAS } & \multicolumn{1}{c|}{ PARTIDO } & $\begin{array}{c}\text { CANTIDAD DE } \\
\text { PÁGINAS }\end{array}$ \\
\hline PASE & Accesibilidad sin Exclusión & 27 \\
\hline PAC & Acción Ciudadana & 188 \\
\hline ADC & Alianza Demócrata Cristiana & 102 \\
\hline FA & Frente Amplio & 198 \\
\hline PIN & Integración Nacional & 51 \\
\hline PLN & Liberación Nacional & 88 \\
\hline ML & Movimiento Libertario & 390 \\
\hline PNG & Nueva Generación & 64 \\
\hline PT & Partido de los Trabajadores & 26 \\
\hline PRC & Renovación Costarricense & 38 \\
\hline PRS & Republicano Socialcristiano & 106 \\
\hline PRN & Restauración Nacional & 56 \\
\hline PUSC & Unidad Socialcristiana & 131 \\
\hline
\end{tabular}

*Todos los programas fueron descargados el 10 de febrero de 2018, de las páginas oficiales de los partidos o las de los candidatos, según fue el caso.

**EI PRN efectuó una 'renovación' de su programa en el contexto de la segunda ronda electoral, al cual denominó "2.0". El primero es considerado para efectos de este trabajo como el plan original. Y, en todo caso, en materia de inmigración, no hubo cambios.

A partir del estudio efectuado a los programas de gobierno, y con el objetivo de establecer la base para la sistematización y análisis de los contenidos base de los discursos sobre inmigración a partir de los marcos de referencia re-activo y pro-activo, se han inferido los siguientes tópicos y categorías correspondientes; en esta tabla se sistematizan las características generales de 
cada uno de estos, desde las ópticas de DR y DP, para posteriormente desarrollar lo encontrado en los documentos partidarios.

De acuerdo a la tabla 1, los tópicos (de A a G) son agrupaciones macro que se ubicaron a partir del levantamiento de la información en los programas de gobierno. Estos devienen de la identificación de las subcategorías presentes para cada tópico.

Para el presente análisis, se debe apuntar que las estructuras de los programas de gobierno son variadas en tanto temáticas, formatos, extensión y demás; es decir, no existe una estructura sugerida ni mucho menos obligatoria y, como resultado, los partidos políticos tienen la libertad de formularlos de acuerdo a su conveniencia e interés. Implica que algunos plantean diagnósticos de los diversos ámbitos de la realidad nacional para, posteriormente, proponer sus soluciones a las problemáticas detectadas. Otros se enfocan en sus propuestas, dejando entrever de forma implícita las situaciones o los retos sobre los cuales proponen soluciones; y, por último, en las temáticas y prioridades también quedan a discreción de los partidos políticos.

Lo anterior es fundamental pues, al entender los programas de gobierno como discursos políticos, toda la información presente es parte de dicho discurso, lo cual conlleva a que los elementos sobre inmigración presentes se infieren de cualquier apartado y son igualmente válidos como parte de un discurso total.

En las siguientes líneas se detalla la categorización y el análisis a partir de los tópicos y las subcategorías ubicadas, a partir de los enfoques de discursos re-activo (DR) y pro-activo (DP).

\section{Interpretación del fenómeno migratorio}

En este tópico se desarrolla de qué forma se concibe el fenómeno de la inmigración. O sea, respondería a la pregunta: ¿qué es la inmigración?; recoge las diversas formas en que los partidos políticos, a partir de sus programas, evidencian su propia percepción sobre la inmigración.

\section{Percepción sobre la inmigración}

En el momento de caracterizar el fenómeno mismo, los programas van perfilando diferencias que, eventualmente se evidencian en el cuerpo de los documentos.

En este sentido, PAC, FA, PIN, PLN, PRC siguen un DP al ubicar a la población inmigrante como población vulnerable, pero no necesariamente su identificación sigue una línea de solución; es decir, no aparecen propuestas concretas para subsanar su condición de vulnerabilidad; por ejemplo, el PAC evidencia tal discurso apelando a la necesidad de la integración de esta pobla- 
ción cuando hace alusión a la "priorización de los Derechos Humanos de las personas migrantes" (73) como una meta prioritaria. Por otro lado, el PIN los denomina "población excluida" y el FA los refiere como "poblaciones cuya inclusión en el mundo laboral remunerado es más difícil” (16).

Por otro lado, PASE, RSC, PRN tienen un DR en tanto interpreta que los inmigrantes son un problema relativo a criminalización, precarismo o son no cotizantes -o evasores- del sistema de seguridad social en tanto personas indocumentadas. En tal sentido, por ejemplo, el PASE propone "se reforzará especialmente la policía de migración y se fortalecerá el centro de detención para indocumentados" (19). El PRN ofrece "fortalecer drásticamente la policía migratoria y hacer del tema "migración" un tema país y, por ende, merecedora de una política nacional consistente y seria, que acabe con la ilegalidad migratoria y permita una mejor lucha contra el crimen transnacional" (36).

En un nivel propio, de la mano igualmente de un DP, el PT entiende en fenómeno migratorio en tanto económico, pero deja en claro que es un fenómeno de personas, con todas las complejidades propias.

\section{Interpretación del migrante}

En este tópico se ubica uno de los fundamentos básicos es análisis de discurso, el cual puede funcionar como un indicador elemental para inferir la posición acerca de la inmigración, esto es la forma en que se llama o se denomina a la persona inmigrante. Van Dijk (s.f.) apunta que el léxico es uno de los componentes propios del análisis estructural del discurso, que provee información importante para discernir posiciones, en este caso políticas.

\section{Nombre y concepción sobre el inmigrante}

En este aspecto, como se desarrolla en la tabla 1, el DR tiende a llamar al inmigrante a partir de su status jurídico y le interpreta de dicha manera; esto también plantea una implícita relación de lejanía entre "ellos" y "nosotros". Entre las palabras más recurrentes, desde un DR, están 'indocumentado', ilegal' (PASE, PIN, ML, PRN), 'extranjero' (PUSC) o 'migrante' (PASE, ADC, PLN, ML, RSC, PRN). La relación es clara en cuanto a la percepción de las calidades eminentemente legales de la inmigración o al menos palabras que expresan lejanía por su neutralidad.

Como bien plantea Zapata-Barrero (2009), el DP tiene formas más diversas de referirse a los inmigrantes. Estas se ubican más en una concepción desde la complejidad de la inmigración, reconociendo alguno o varios elementos relacionados con esta población, más allá de lo eminentemente legal. Desde tal óptica, formas en las que la condición de persona está antes de la de inmigrante se observa en: 'personas migrantes', 'personas inmigrantes' o sus plurales -incluyendo 'familias migrantes' (PAC, FA, PRC), así como referencias 
a situaciones relacionadas al proceso mismo de la inmigración como 'refugiados'1 (PAC, ADC), 'víctimas de trata' (PAC) y, particularmente, el PT lo habla 1. Aunque ser "refugiado" es exclusivamente como 'nicaragüense'.

\section{Actividades del inmigrante}

una condición legal, en el contexto que se utiliza como referencia a inmigrante es en función de su posición como población vulnerable, por lo cual se considera un DP.

En estrecha relación con el punto precedente, esta subcategoría recoge los discursos acerca la percepción de lo que el inmigrante hace o llega a hacer al país de destino, en este caso Costa Rica. Cabe aclarar que se privilegió la forma explícita en que cada programa definía o comprendía las actividades del inmigrante en el país; es decir, que lo hiciera patente. Solamente cuatro partidos -PAC, PT, FA y RSC- identificaron en sus programas actividades del inmigrante en el país.

Los tres primeros se identifican dentro de un DP por cuanto ubican al inmigrante como parte de la fuerza laboral del país, un componente en el desarrollo económico propiamente, particularmente el PAC, que incluso lo caracteriza como un "potencial emprendedor". Por su parte, la posición del RSC no es fácilmente ubicable en su discurso con respecto a DP o DR por cuanto el inmigrante es un "trabajador informal", pero no especifica las causas de ello.

\section{Ley y política migratoria}

Comprender las orientaciones propias de las políticas migratorias presentes en los programas o bien la forma en que el discurso partidario entiende la labor de la política pública relativa a la inmigración, ayuda a entender cuál es la visión de la inmigración desde el marco que la regula. A partir de lo encontrado, se infieren dos subcategorías: objetivos -que responden a: ¿cuáles son los objetivos de la una política migratoria?; y debilidades, que responde a la pregunta: ¿cuáles son las debilidades de la política migratoria actual?

\section{Objetivos}

De forma explícita, únicamente dos partidos hacen alusión a políticas migratorias, PAC y PUSC. En ese sentido, el DP enfoca las políticas migratorias desde el humanismo y los Derechos Humanos. En este caso, el PAC plantea un discurso sobre este tipo de políticas como medios para integrar a la población inmigrante, elemento intrínseco de un paradigma de derechos humanos; precisamente, el PAC habla de una:

Reforma a la ley de Migración y Extranjería en el tema de los montos económicos para facilitar el derecho a acceder al trámite para regularizar la condición migratoria en 
el país, de manera equitativa de acuerdo con los ingresos de las personas extranjeras, y que permita a la agilidad, la transparencia y la formalización (73).

En cambio, como ya se ha explicado, un DR ve la política migratoria como el coordinador normativo de la restricción al ingreso. Así, el PUSC privilegia su discurso de esta política como el responsable del bloqueo a la inmigración, aludiendo a una inmigración criminalizada y abogando por más controles de ingreso.

\section{Debilidades}

En este apartado, solo dos partidos hicieron algún tipo de referencia, ambos desde la crítica. El PAC y el PT vuelven sobre un DP en tanto critican la política migratoria como discriminatoria, abusiva y denuncia, particularmente el PAC, al afirmar que los montos establecidos allí para la estadía del inmigrante son excesivos. Precisamente, el PT denuncia que existe un "excesivo trámite migratorio, en los que se requiere una validación constante de la documentación en Nicaragua que implican costos de traslado y viáticos" (p. 21).

\section{Política exterior}

Es importante destacar en este aspecto que la propuesta teórica de ZapataBarrero no alude directamente a la política exterior en particular. Pero para efectuar un aporte en este sentido, sí es válido entender los tópicos que él desarrolla en su obra y de allí tomar elementos para la construcción de una estructura básica de los DR y DP en política exterior en relación con el fenómeno de la inmigración.

En sentido, derivado de lo encontrado en los programas de gobierno estudiados, como se sistematiza en la tabla 1, un DR con respecto a política exterior en materia de inmigración implicaría estimular una restricción a los flujos migratorios en los foros internacionales. Por su parte, un DP interpreta la política exterior en función de la integración de los inmigrantes en la sociedad de acogida, propugnando la normalidad del proceso migratorio.

Asimismo, el DR se establece en fomentar acuerdos bilaterales o multilaterales en términos de seguridad de fronteras, en tanto el DP ubica estos acuerdos desde una óptica de desarrollo conjunto, humanitario y desde los derechos humanos. 


\section{Relación con la población inmigrante}

La relación de la política exterior y la inmigración únicamente es planteada, de forma muy general, por tres partidos políticos: PAC, PLN y PRN. Estos partidos se expresan en un principio un DP por cuanto el PAC alude a una obligatoriedad de Costa Rica para liderar a la comunidad internacional en la defensa de los derechos de la población inmigrante. El discurso del PLN va sobre la línea de fomentar cooperación internacional que facilite la integración de la población inmigrante; puntualmente, plantea a la migración como un 'área temática prioritaria' de la política exterior.

Finalmente, el PRN, aunque de forma general, apunta que la política exterior debe estar apegada a los derechos fundamentales de los inmigrantes.

\section{Temas básicos}

En este apartado se agrupan diversas temáticas relacionadas usualmente tanto con política pública y con inmigración, al tiempo que son temas de discusión permanente en diversos espacios formales e informales en debates sobre política; de allí su colocación como 'básicos'.

\section{Servicios públicos}

A pesar de ser uno de los temas aglutinadores más debatidos en las campañas electorales, en función de su relación con la población inmigrante, en términos generales, se relaciona poco. También cabe apuntar que la generalidad de lo encontrado interpreta servicios públicos como servicios de asistencia social.

Cabe recordar que el DP entiende a los inmigrantes como beneficiarios de los servicios públicos en razón de su calidad de personas antes que su situación migratoria o de otra índole. Asimismo, tal discurso comprende al inmigrante como una parte activa o potencial de la sociedad y, por ende, los servicios públicos deben contemplarlos como usuarios.

En esta línea se ubica el PAC, que particularmente comprende los servicios públicos (y alianzas de estos) como medios integradores de los inmigrantes en la sociedad; en su programa, el PAC apunta: "desarrollar alianzas públicoprivadas, incluyendo centros de estudios y organizaciones no gubernamentales (ONG) para dar capacitaciones y atención para superar las brechas idiomáticas y culturales de las personas migrantes recién llegadas, contemplando los trabajos comunales y programas de responsabilidad social empresarial" (74).

EI PT especifica a la población inmigrante como una víctima de la alta burocratización para estar en regla y poder ser beneficiarios; expresa en su plan: " $¡$ Todos los derechos para todos los migrantes! Acceso gratuito a todos los 
servicios de salud de la CCSS para todas las personas, sin importar su nacionalidad o condición migratoria en el país" (21). Por último, en relación con el servicio de la educación, el PLN apunta: "Fortaleceremos la educación multicultural y adecuada a las necesidades y condiciones de las poblaciones indígenas, afrodescendientes y migrantes" (65), y el FA expresa: "Se incluirá la educación sobre las culturas indígenas, afrodescendientes y en general sobre el carácter multiétnico y pluricultural de nuestro país, así como sobre el respeto a los derechos humanos de las personas migrantes" (65); esto evidencia un énfasis en la importancia del acceso de esta población a la educación por parte de estos partidos.

EI DR, como ya se ha apuntado, entiende los servicios públicos en dos términos: por una parte, una línea de legalidad; en otras palabras, el acceso a servicios debe estar antecedido por una condición de regularidad migratoria. Y el otro término es en cuanto a interpretar a los inmigrantes como abusadores del sistema.

En esta línea, se encontró el discurso del ML, que entiende a los inmigrantes como 'saturadores' de los servicios públicos, en particular del sistema de salud; de hecho, profundiza el DR en tanto los servicios de asistencia social debería ser exclusivamente para costarricenses. Su plan indica que "muchos migrantes sin seguro de enfermedad y maternidad saturan los servicios de emergencia de los hospitales y clínicas afectando el servicio que se brinda a los asegurados" (185). Asimismo, el PRN divide a los inmigrantes entre "cotizantes' y 'no cotizantes', y caracteriza a los inmigrantes como los que saturan los servicios de salud, asistencia, vivienda y educación.

\section{Desarrollo}

¿Cómo se interpreta la relación entre la inmigración y el desarrollo? En este sentido, el DP comprende al inmigrante como un componente activo del desarrollo y como sujeto de derechos. Un elemento importante del DP es que ese componente del desarrollo -eminentemente desde el ámbito laboral- es a su vez una persona.

El DR también comprende al inmigrante en términos de componente laboral del desarrollo, pero con una visión siempre colectiva, la conocida "fuerza laboral", evitando una humanización e individualización del mismo. Igualmente, la interpreta como una fuerza de 'reserva' pues debe llenar estrictamente los espacios laborales que no son llenados por los nacionales.

En este aspecto, el DP está más representado en los programas de PAC, PT y FA; estos dos últimos, incluso, expresan que la población inmigrante es usualmente víctima de abusos laborales. Sobre este tema, el PT, por ejemplo, especifica que "la población trabajadora nicaragüense es un sector fundamental que forma parte de las labores en sectores de construcción, turismo, agricultura, manufactura, comercio y demás" (p. 20). 
El otro partido que hace alguna mención del tema es $M L$, pero únicamente se limita a reconocerlos como fuerza laboral.

\section{Seguridad}

Este apartado es quizá el más claro en relación a las diferencias sobre el DR y DP. EI DR interpreta al inmigrante desde la óptica eminentemente de seguridad, como ya se ha apuntado. Desde el punto de vista del DR, varios de los programas de gobierno plantean sus principales planteamientos a partir de este criterio. PASE, PLN, ML, PRN y PUSC hacen referencia a la necesidad de un reforzamiento de política migratoria, pero esto es entendido como un reforzamiento en los criterios de ingreso; igualmente, se aclara más cuando aluden a un fortalecimiento de la Policía de Migración, como indica, por ejemplo, el plan del PUSC, sugiere, con respecto a la inmigración, a "fortalecer los diferentes cuerpos policiales: la policía preventiva, la represiva y la penitenciaria" (19).

Es clara la postura en el endurecimiento y restricción en el ingreso, así como facilitación en la salida. Particularmente, el PUSC infiere a los inmigrantes como criminales en potencia.

Únicamente el PAC intenta equilibrar, desde un DP, el criterio de seguridad con la promoción de los derechos humanos como eje transversal en la preparación de la Policía de Migración. Explícitamente, plantea que si bien el enfoque de seguridad tiene una relación directa con los fenómenos migratorios, no debe ser el único criterio para entender la inmigración.

\section{Reconocimiento de derechos}

Este apartado expone los discursos que tienen una relación con las posiciones acerca del reconocimiento de derechos a la población inmigrante. Como se expone en la tabla 1, una diferencia sustancial es que el DP entiende los derechos como un elemento intrínseco -pues basan su discurso en el paradigma de los Derechos Humanos-y por ende se reconoce. EI DR entiende los derechos como una prerrogativa total de la voluntad política y no es algo automático ni mucho menos de un nivel igual al de los nacionales.

\section{Derechos que deben reconocerse o profundizarse}

EI DP se ve presente en el programa del PT en tanto considera que los derechos políticos de la población nicaragüense deben ser reconocidos, por ende, se alude a la desigualdad en el reconocimiento en función de los nacionales de Costa Rica. En una línea común, el PAC y FA refieren que los inmigrantes tienen el derecho a ser legalizados; en particular el PAC insta a "me- 
jorar la coordinación del MTSS y la DGME para regularizar a la población migrante trabajadora" (p. 73).

EI DR no está presente de forma clara. EI PIN hace referencia a que es obligación del inmigrante buscar legalizar su situación.

\section{Apuntes finales}

Los programas de gobierno, como hemos apuntado, son discursos políticos. Lo anterior define, por ende, que asumen o dirigen una acción política, esta devenida de muchos criterios: principios y valores, estrategia política, intereses, ideología partidaria, tradición, ubicación entre oficialismo y oposición, entre lo básico. Entonces, se define la posición sobre todos los temas, desde los básicos a los complejos o polémicos.

La inmigración es un tema siempre delicado -particularmente para países de tránsito y destino-pues confluyen ámbitos como el económico, el social, seguridad, derechos humanos, entre otros, lo cual a su vez se entendería que debería reflejarse en los programas de los que quieran ostentar el poder político.

El hecho de que sea un tema tan trascendental, pero a su vez tan delicado en muchas sociedades, se vuelve una paradoja en tanto no siempre es parte del debate político -a pesar de su potencial necesidad- salvo que devenga de una situación considerada crítica, como migraciones masivas permanentes o inusuales, desastres naturales, o bien la utilización del fenómeno como recurso discursivo para la captación de capital político.

Costa Rica es un país cuya tradición socioeconómica tiene una relación directa con el fenómeno de la migración, sea tanto como expulsor de sus nacionales o como receptor de poblaciones inmigrantes, como se apunta en el Diagnóstico del Contexto Migratorio 2017 (2017, 12):

El crecimiento de inmigrantes de otros países ha aumentado el universo total de inmigrantes, pero no ha reducido el peso de los nicaragüenses en ese conjunto, la preeminencia de la inmigración nicaragüense hace que las características del conjunto de la población inmigrada en Costa Rica aparezcan apreciablemente determinadas por dicho fenómeno, pero es necesario no perder de vista que las condiciones sociodemográficas de un jubilado norteamericano o de un inversor colombiano no son las mismas que las de un trabajador nicaragüense. 
Tal relación con la migración, particularmente con la inmigración, ha significado la inclusión de un sector importante en el desarrollo socioeconómico del país. Pero, a su vez, la convivencia y percepción sobre algunas poblaciones migrantes específicas -en cuenta la nicaragüense-, ha planteado retos en su integración.

Dicho contexto nacional debe ser tomado en cuenta por los formuladores de política pública al momento de gestionar procesos migratorios ordenados, seguros y respetuosos de los derechos humanos, entendiendo esta última característica como un fundamento de la política interna y exterior del país.

Sobre los casos estudiados en el presente trabajo, puede observarse una variedad amplia de forma y fondo en los programas de gobierno de los 13 partidos políticos de la contienda electoral costarricense de 2018. Desde el programa del PNG, que no menciona absolutamente nada sobre inmigración o emigración, hasta planes como los del PAC y FA que desarrollan (siempre de forma muy breve) apartados enfocados en la relación del fenómeno de la inmigración en Costa Rica.

A partir de la herramienta utilizada, se revela una igualmente variada concepción discursiva de los migrantes en particular y la inmigración en general, y su relación con la realidad político-social y económica del país.

De hecho, en concordancia con tendencias al pragmatismo en las propuestas ideológicas de los partidos políticos en muchos países, así como el indiscutible peso de los procesos globalizadores económicos y culturales en el mundo contemporáneo, la discusión política se está enfocando, como apunta acertadísimamente Ernst Hillebrand (2017), ya no en la añeja discusión cuasi maniquea de izquierda y derecha, sino por la oposición entre 'cosmopolitas' y 'comunitaristas'. Los primeros son hijos exitosos de la globalización, y entienden la inmigración como un proceso de oportunidades y enriquecimiento, concordante con el discurso pro-activo, mientras que los últimos centran su defensa en el Estado nacional tradicional, que enfocan con recelo los procesos inmigratorios, interpretándolos como una potencial competencia por recursos monetarios y laborales cada vez más escasos, fundamentalmente un discurso re-activo.

Esa dualidad puede verse reflejada en los resultados del análisis discursivo de los programas de gobierno, por cuanto se evidencia en el desagregado temático, que se oscila entre una compresión de la inmigración más enfocada en los derechos humanos de las personas migrantes y en su aporte al sistema productivo; y otra como mano de obra necesaria, pero a la vez un sujeto en permanente vigilancia, que constantemente debe demostrar su inocencia.

Queda todavía un reto grande en el abordaje sistemático y global del fenómeno de la inmigración desde los programas de los partidos políticos. En la gran mayoría de los programas, su abordaje marginal, con una pobre especificidad y poca claridad, no aporta realmente a la compresión e integración de la inmigración y le dejan en espacio de la oscuridad. 
En Costa Rica, discursivamente, los partidos políticos centran sus programas en aspectos muy específicos de la migración, desarticulados de la inmigración como un fenómeno multicausal y transversal en el desarrollo de la sociedad. En particular, el discurso re-activo encontrado reconoce muy pocos elementos más allá del inmigrante como mano de obra, como se mencionó, que implica desconocer situaciones complejas detrás del proceso de la inmigración. Por otra parte, el discurso pro-activo presente intenta reconocer esa complejidad, pero en lo programático el discurso no es satisfactoriamente traducido a propuestas concretas.

\section{Bibliografía}

Alvarenga Venutolo, Patricia. 2008. «La inmigración extranjera en la historia costarricense». En El mito roto, editado por Carlos Sandoval García, 324. San José: EUCR.

Dalmases, Jordi. 2005. «Los partidos políticos y los sistemas de partidos». En Manual de Ciencia Política, editado por Miquel Caminal, 317-342. Madrid: Tecnos.

DGME. 2012. Informe sobre Migración e integración en Costa Rica. San José: DGME.

Dobles Oropeza, Ignacio, Vargas Selva, Gabriela, Amador Rojas, Krissia. y Arroyo Sibaja, Estado de la Nación. 2016. Vigésimo Segundo Estado de la Nación. San José: Estado de la Nación.

Duverger, Maurice. 1996. Los partidos políticos. México: Fondo de Cultura Económica.

Hillebrand, Ernst. 2017. «La encrucijada socialdemócrata. Entre la globalización y el Estado nacional». Nueva Sociedad. 271: 110-116.

Jäger, Siegfried. 2003. «Discurso y conocimiento: aspectos teóricos y metodológicos de la crítica del discurso y del análisis de dispositivos». En: Métodos de análisis crítico del discurso. Editado por Ruth Wodak y Michael Meyer, 61-101. Barcelona: Gedisa.

Massiel. 2013. «La inmigración y el Poder Legislativo en Costa Rica: Discursos y acciones políticas». Reflexiones. 92: 97-108.

Matus, Carlos. 2007. «Escuela de Gobierno». Salud colectiva. 3: 203-212.

Molina, Ignacio. 2007. Conceptos fundamentales de Ciencia Política. Madrid: Alianza Editorial.

Morales, Abelardo (coord.). 2014. Escenarios sociopolíticos de las migraciones en Costa Rica y Colombia. San José: FLACSO.

OCDE/OIT. 2018. Cómo los inmigrantes contribuyen a la economía de los países en desarrollo. París: Éditions OCDE. 
OIM. 2019. ¿Quién es un migrante? Accesado el 18 de marzo de 2019. https://www.iom.int/es/quien-es-un-migrante

Oñate, Pablo. 2003. "Los partidos políticos". En Manual de Ciencia Política, editado por Rafael del Águila, 251-270, Madrid: Tecnos.

PNUD, NDP 2015. Orientaciones para la construcción de planes de gobierno. Bogotá: PNUD.

SICREMI 2015. Tercer informe sobre la Migración internacional en las Américas. Washington: OEA.

Van Dijk, Teun. s.f. «Discurso y racismo». Accesado el 20 de agosto. http://www.discursos.org/oldarticles/Discurso\%20y\%20racismo.pdf

Van Dijk, Teun. 1993. Texto y contexto. Madrid: Cátedra.

Zapata-Barrero, Ricard. 2007. «Política del discurso sobre inmigración en España: discurso re-activo y pro-activo en los debates parlamentarios». Discurso y Sociedad. 1: 317-369.

Zapata-Barrero, Ricard. 2009. Fundamentos de los discursos políticos en torno a la inmigración. Madrid: Trotta.

Zapata-Barrero, Ricard., González, Elizabeth. y Sánchez, Elena. 2008. El discurso político en torno a la inmigración en España y la Unión Europea. Madrid: Ministerio de Trabajo e Inmigración. 